\title{
Erratum
}

Int Neurourol J 2011;15:179-180

http://dx.doi.org/10.5213/inj.2011.15.3.179

pISSN 2093-4777 · eISSN 2093-6931

\section{Urodynamic Findings in an Awake Chemical Cystitis Rat Model Observed by Simultaneous Registrations of Intravesical and Intraabdominal Pressures}

Long-Hu Jin, Hwa-Yeon Shin, Yong-Hyun Kwon ${ }^{1}$, Chang-Shin Park ${ }^{1}$, Sang-Min Yoon and Tack-Lee

Three parts of the published article should be corrected as follows.

\section{In Table 2, the values for $\%$ of AS to IVPRs and $\%$ of DO to IVPRs for the IC group should be 43.7 and 56.3, respectively, as shown in the corrected table below}

Table 2. Characteristics of intravesical pressure rise above $2 \mathrm{cmH}_{2} \mathrm{O}$ during the filling phase in awake SD rats in the sham and interstitial cystitis (IC) groups

\begin{tabular}{cccccccc}
\hline Group & $\begin{array}{c}\text { Time of } \\
\text { filling phase } \\
\text { min }\end{array}$ & $\begin{array}{c}\text { Frequency } \\
\text { of IVPRs } \\
\mathrm{min}^{-1}\end{array}$ & $\begin{array}{c}\text { Frequency } \\
\text { of AS } \\
\mathrm{min}^{-1}\end{array}$ & $\begin{array}{c}\text { Frequency } \\
\text { of DO } \\
\mathrm{min}^{-1}\end{array}$ & $\begin{array}{c}\text { \% of AS } \\
\text { to IVPRs }\end{array}$ & $\begin{array}{c}\text { \% of DO } \\
\text { to IVPRs }\end{array}$ & $\begin{array}{c}\text { Increased Pr. of DO } \\
\text { peak from baseline } \\
\left(\text { IVP. cm } \mathrm{H}_{2} \mathrm{O}\right)\end{array}$ \\
\hline $\begin{array}{c}\text { Sham } \\
(\mathrm{n}=6)\end{array}$ & $6.7 \pm 0.5$ & $0.7 \pm 0.1$ & $0.7 \pm 0.2$ & 0 & 100 & 0 & 0 \\
$\begin{array}{c}\text { IC 2W } \\
(\mathrm{n}=7)\end{array}$ & $11.3 \pm 1.2^{*}$ & $1.6 \pm 0.5^{*}$ & $0.7 \pm 0.2$ & $0.9 \pm 0.5^{*}$ & $\underline{43.7}$ & $\underline{56.3}$ & $3.1 \pm 1.0^{*}$ \\
\hline
\end{tabular}

IVP, intravesical pressure; IVPR, IVP rises during the filling phase; AS, abdominal straining; DO, detrusor overactivity; Pr., pressure; IC, interstitial cystitis. Results are expressed as mean \pm standard error of the mean. ${ }^{*} \mathrm{p}<0.05,{ }^{\star *} \mathrm{p}<0.01$ (unpaired Student's t test), versus the sham group. 


\section{The legend of Figure 2 should be corrected as shown below}
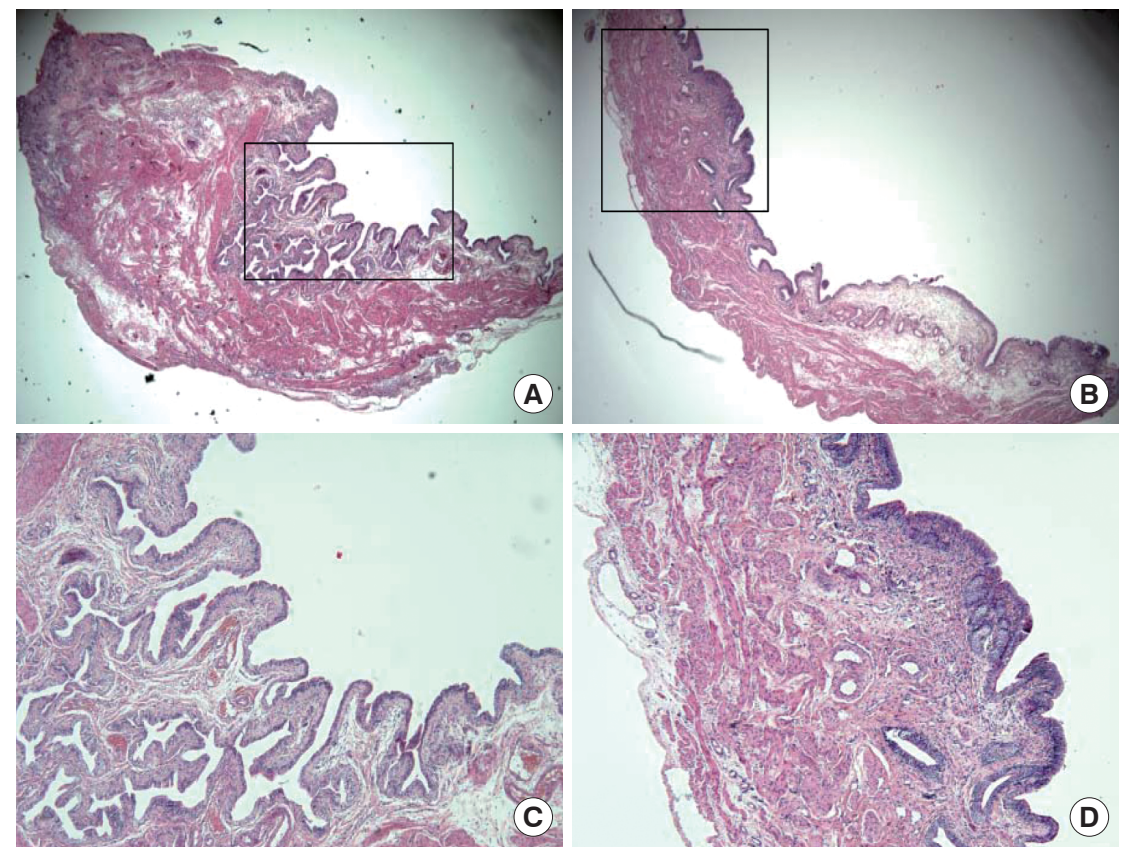

Fig. 2. Microphotograph showing the histologic sections of rat urinary bladder after hydrochloric acid $(\mathrm{HCl})$ injection, stained with hematoxylin and eosin. Sham $(\mathrm{A}, \mathrm{C})$ and $\mathrm{HCl}$ treatment $(\mathrm{B}, \mathrm{D})$. $\mathrm{C}$ and $\mathrm{D}$ show the small boxes of $\mathrm{A}$ and $\mathrm{B}(40 \times)$ at a higher magnification of $100 \times$, respectively.

\section{The sentence at the bottom of the right column on 59 page should be} corrected as follows.

We objectively confirmed, by simultaneous registrations of intravesical and intraabdominal pressure, that DO made up $\underline{56.3 \%}$ of the total IVPR frequency. 